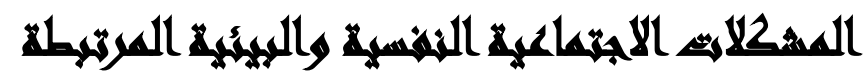

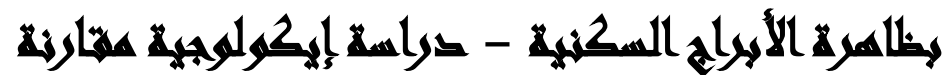

\section{[1.]}

عبد الباسط محمد عبد المعطى(')- حسن قطرى محمد نزهه(r)-- سامح سعيد عبد العزيز (r)

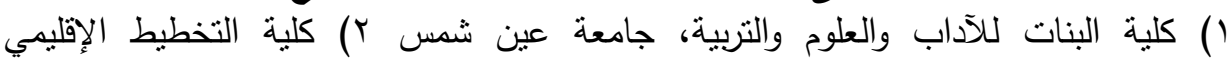

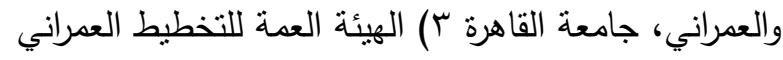

\section{(ll}

تهدف الدراسة إلي التعرف على المشكلات الاجتماعية النفسية والبيئية المرتبطة بظاهرة الأبراج السكنية من خلال دراسة إيكولوجية مقارنة لساكني الأبراج السكنية في مناطق مختلفة الأنة

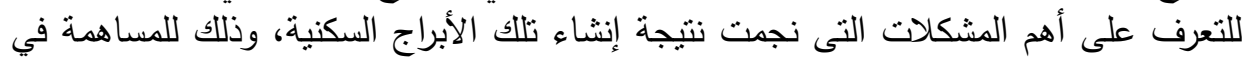
الوصول إلي حلول لها أو التقليل من آثارها أو الحد من تفاقمها إن أمكن مستقبلاً.

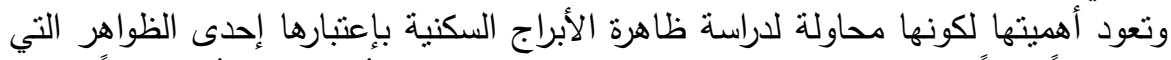

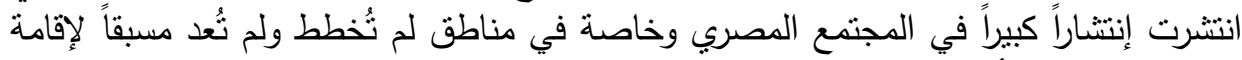
هذه الأبراج مما أدى لظهور العديد من المشكلات منها مشكلات اجتماعية ونفسية وبيئية

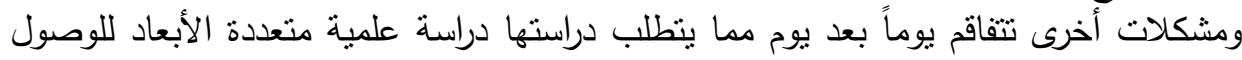
إلي حلول فعالة لمواجنتها.

وقد اعتمدت الدراسة على المنهجين الوصفي التحليلي والمقارن حيث تم اجن اختيار عينة مقدارها ( (10) مفردة قسمت لـ(V0) مفردة لكل منطقة من ساكني الأبراج بمنطقتي حلمية الزيتون والمطرية.

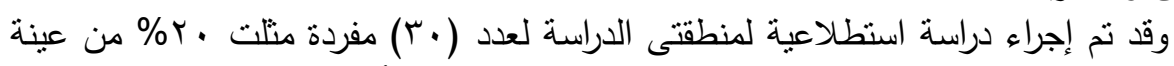
الدراسة قسمت بالتساوى بينهما، واستخدمت الدراسة العديد من الأدوات منها إستمارة الاستبيان

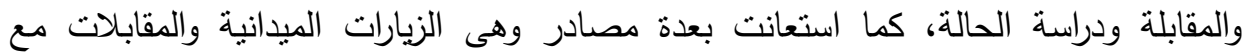
الخبراء وكذلك الوثائق والسجلات والصور والخرائط.

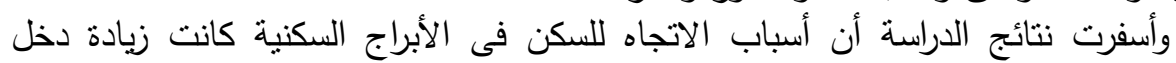

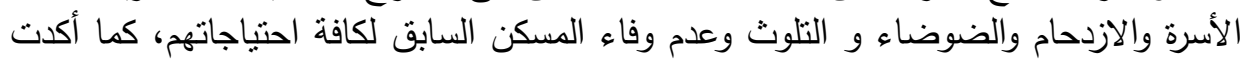

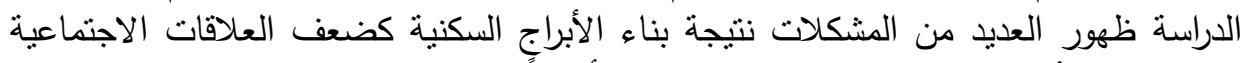

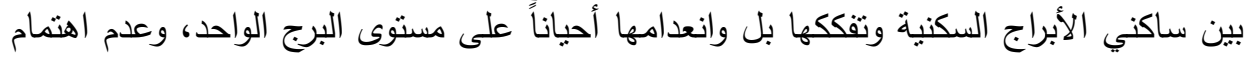
سكانها بصيانة المرافق، وعدم مراعاة الخصوصية عند تصميم معظمها وعدم تحقيقها لمتطلبات 
الأطفال المختلفة، بالإضافة إلى أنه بإنقطاع الكهرباء عنها يتوقف كل شيء فيها تماماً من كهرباء ومياه ومصاعد .. الخ.

\section{مهام}

سحرت المباني والأبراج العالية عقول البشر منذ الأزل فقد كانت ثُشيد أساساً لأغراض

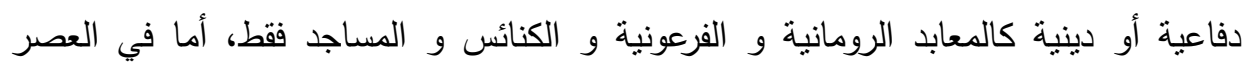

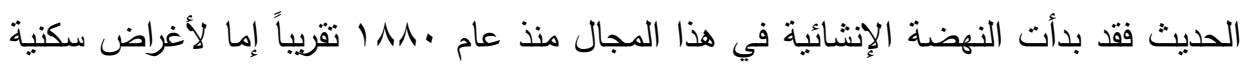
أو تجارية، بل وأصبحت منذ تسعينات القرن العشرين من منشآت الحضارة والتمدن و باتت تمثل فئل

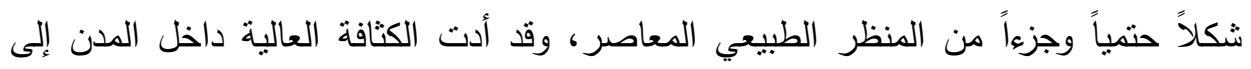

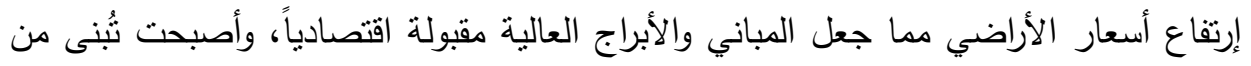

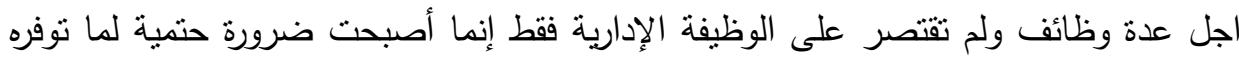

من مساحات الأراضي المحدودة ( ) 2002) وأصبحت المباني والأبراج العالية تقام بشكل مستقل على جوانب الأنهار والبحار والمحيطات وهذا هو النمط الغالب فى المناطق المفتوحة أو فى بعض المناطق بالمدن الجديدة

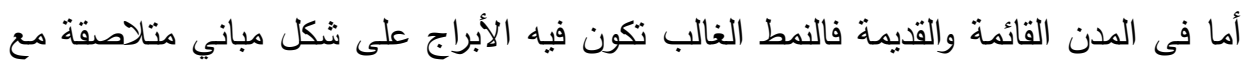

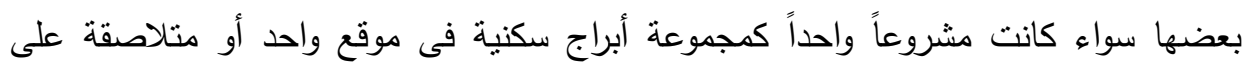

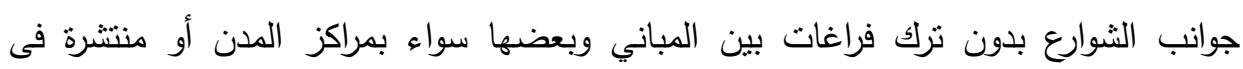
المواقع المختلفة (Hok, 2006) ومع زيادة المبانى السكنية العالية ظهرت العديد من المشكلات الجديدة وتعقدت مشكلات موجودة حالياً منل النقص الواضح فى كفاءة المرافق العامة والضغط عليها سواء مياه ولئه وصرف

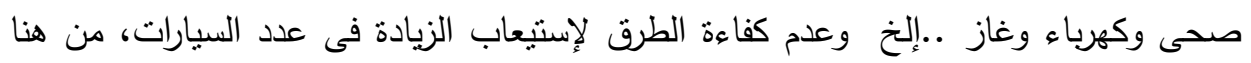

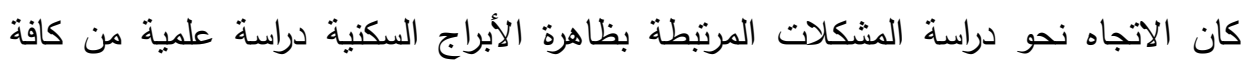
الأبعاد والجوانب. الجاه. 


\section{مشفحلة التراسلة}

ظهرت فى فترة ما بعد حرب أكتوبر عام rو 1 أعداداً كبيرة من المبانى العالية فى معظم

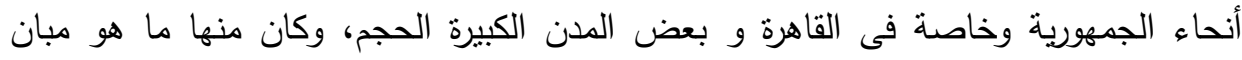
إدارية ومعظمها ما هو من عمارات وأبراج سكنية عالية وإنتشرت ظاهرة هدم المنازل و الفيلات

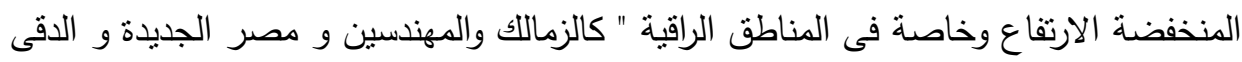

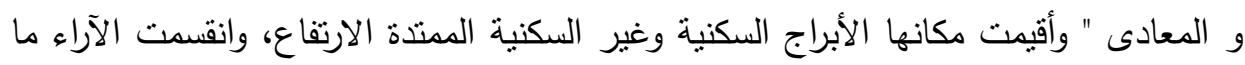
بين مؤيد ومعارض لقيام منل هذه الأبراج ليس فقط علي مستوي المتخصصين بل وكذلك علي وغير التئ

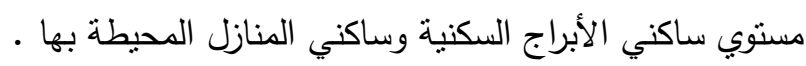

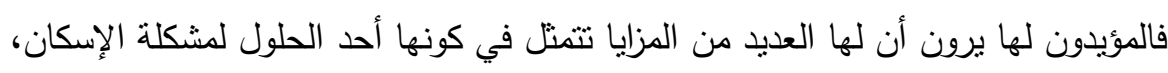
إلي جانب أنها نوسعاً رأسياً يوفر المساحات الأخرى من الأراضي لاستثمارها في نواحي أخرى. لإنيا.

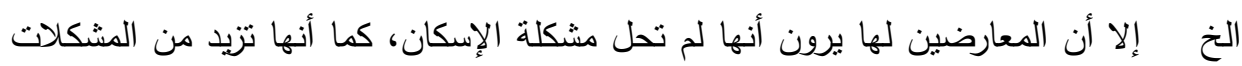

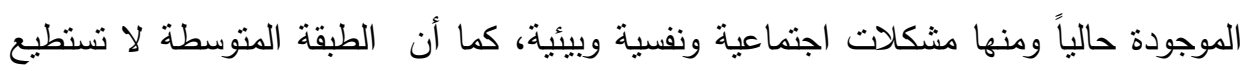

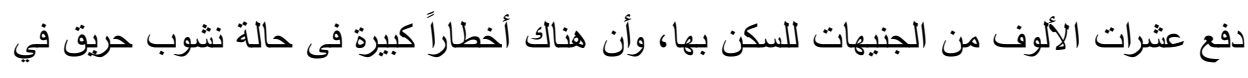

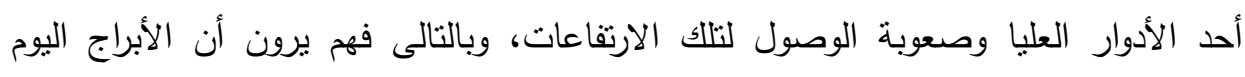

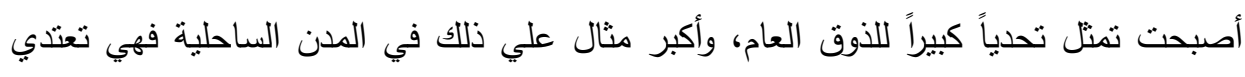

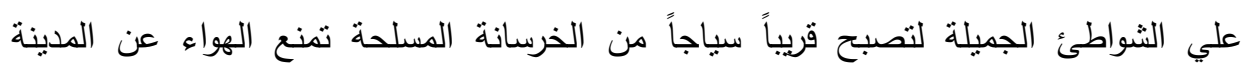

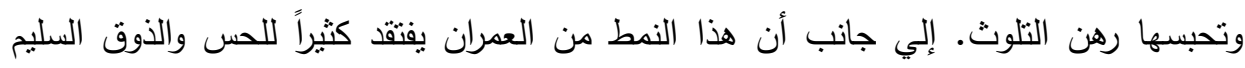
ليحل محله الربح السريع والوفير، وبالتالى فلقد أصبحت تلك الظاهرة ظاهرة عامة نطرح العديد من النساؤلات منها:

هل هناك علاقة بين إنشاء الأبراج السكنية وبين ظهور مشكلات جديدة أو تفاقم مشكلات كامنة؟ وهل هناك إختلاف بين المشكلات وبخاصة المشكلات الاجتماعية والنفسية والبيئية المرنبطة بظاهرة إقامة الأبراج السكنية؟ وهل يمكن وضع تصور مقترح لإيجاد حلول لهذه الظاهرة والمشكلات الناجمة عنها للحد منها مستقبلاً. 
فمن خلال المشاهدات الفعلية أثناء إجراء الدراسة الاستطلاعية والتى شملت عدد (•r) مفردة

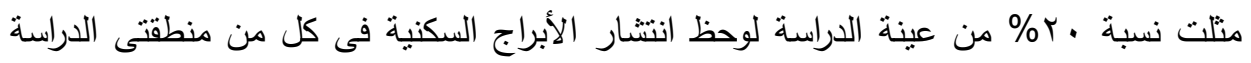

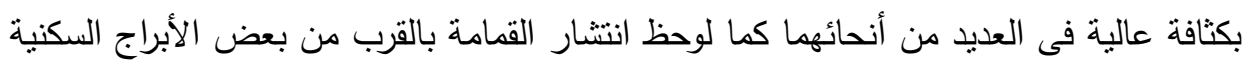

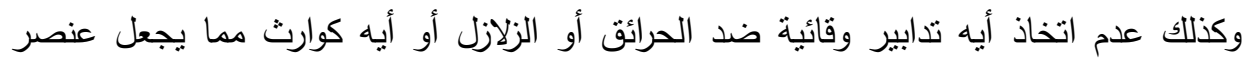

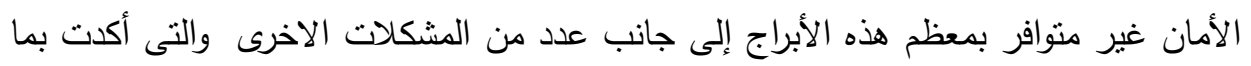

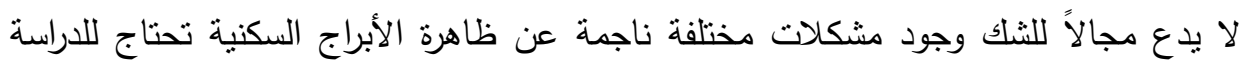

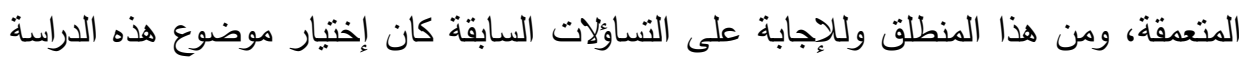
وهو: المشكلات الاجتماعية النفسية والبيئية المرتبطة بظاهرة الأبراج السكنية "لراسة السانة

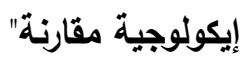

\section{تصاوزلاه التصراسة}

1-1ا الما الشكلات الاجتماعية المرتبطة بظاهرة الأبراج السكنية؟

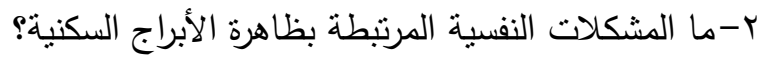

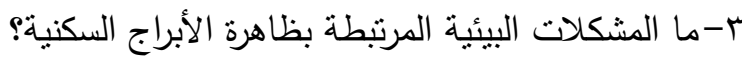

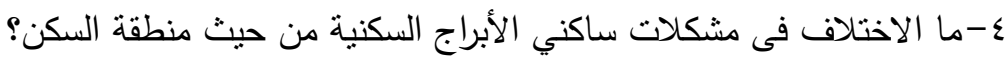

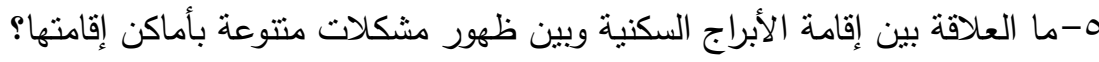

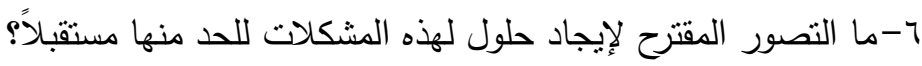

\section{أهفاهي القواسمة}

1- التعرف علي أهم الشكلات الاجتماعية المرتبطة بظاهرة الأبراج السكنية. r- r- التعرف علي أهم المثكلات النفسية المرتبطة بظاهرة الأبراج السكنية. r- التعرف علي أهم المشكلات البيئية المرتبطة بظاهرة الأبراج السكنية. ع - التعرف علي نوعية المشكلات الأخرى المرتبطة بظاهرة الأبراج السكنية.

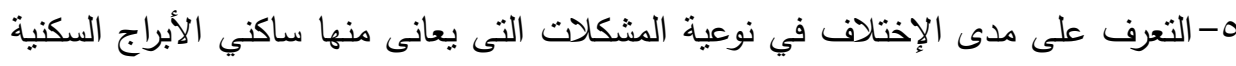
في مناطق مختلفة. 
צ-محاولة وضع تصور مقترح لإيجاد حلول فعالة لهذه المشكلات لتلافي حدوثها أو التقليل من حدتها أو حلها بشكل كامل.

\section{أهمه القدواسمة}

تنبع أهمية هذه الدراسة من خلال ما يلي:

1-كونها محاولة لدراسة إحدى الظواهر في المجتمع المصرى ألا وهى ظاهرة الأبراج السكنية وما قد ينجم عنها من مشكلات وخاصة المشكلات الإجتماعية والنفسية والبيئية.

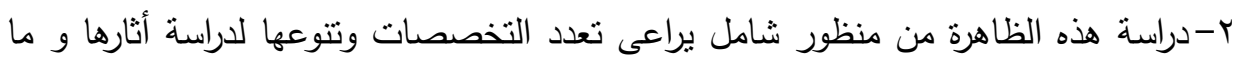

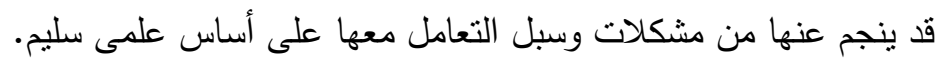
r-حاجة المجتمع المصرى لمنل هذه النوعية من الدراسات الثاملة وذللك للوصول إلي فهر صحيح لكافة الظواهر مما يساعد على الوصول إلي حلول فعالة لها.

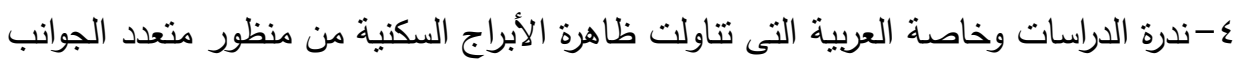
وما قد ينجم عنها من آثار سلبية مما يزيد من أهمية هذه الدراسة.

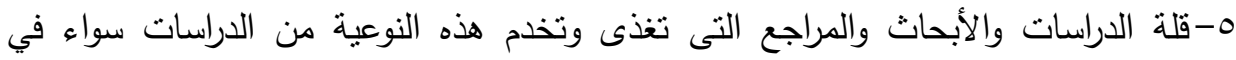

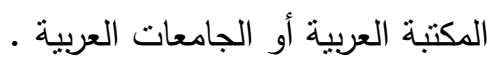
وتجدر الإشارة إلى أن العديد من الجهات يمكن أن تستقبد من هذه الدراسة فعلي سبيل المثال: وزارة الإسكان والمرافق والمجتمعات العمرانية وهيئة المجتمعات العمرانية الجديدة والهيئة العامة للتخطيط العمراني ووزارة التتمية المحلية ومعهد بحوث البناء والإسكان ومديريات الإسكان والمحليات بالمحافظات بالاضافة إلى جانب الجامعات و المراكز والجهات البحثية

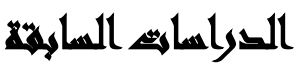

أشارت دراسة منى أحمد عبد الله(10 + ب) بعنوان "الأبراج السكنية بين الثكل والمضمون ومراعاتها لاحتياج خصوصية الإنسان فى التصميم"؛ إلي أن دراسة الأبراج السكنية من حيث التصميم الداخلى لكل برج و معرفة إلى أى ددى حقق تصميم هذا البرج

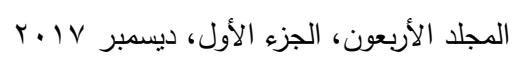


الاحتياجات الإنسانية و بشكل خاص الخصوصية بين أفراد الأسرة الواحدة و بين الجيران بعضهم البعض وعرضت الدراسة بعض أسباب عدم بناء الأبراج السكنية شاهقة الارتفاع فى الإنى

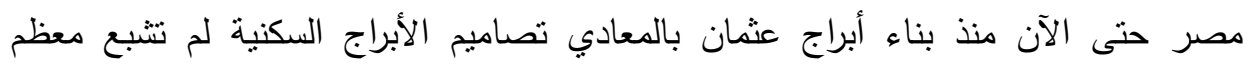

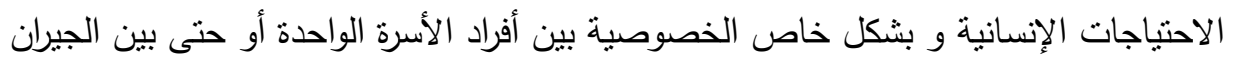
وفى دراسة منى عوض الوزير(ب ا ب r) بعنوان نحو منهجية مقترحة للحد من التوسع العمراني الرأسي للمدن المصرية بعد ثورة هب يناير دراسة حالة ” ظاهرة بناء الأبراج السكنية

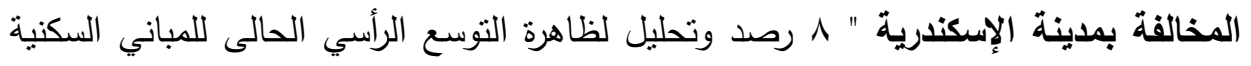

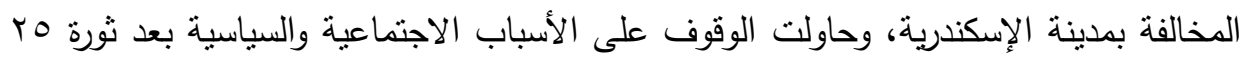

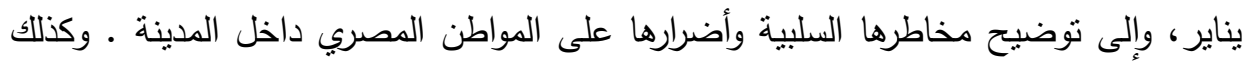
وضع تصور منهجي عملي للحد من تلك الظاهرة، كما أكدت على أهمية دور الدولة ومؤسساتها التشريعية فى التشريع والرقابةً ومدى مساهمة وسائل الإعلام فى ذلك ودورها الإيجابي فى توعية الفرد والأسرة لمعالجة الآثار السلبية الناجمة عن هذا النمو العمراني وتحقيق العدالة المعمارية

$$
\text { المنشودة فى المجتمع المصري. }
$$

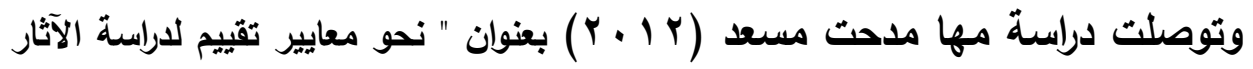

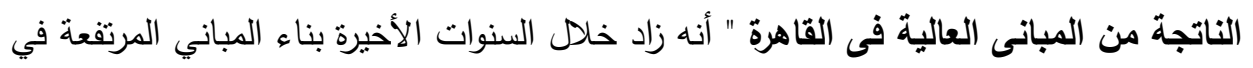
جميع أنحاء العالم، وأن المباني عالية الارتفاع هي ذات نطاق فريد من نوعه كحل ناجح لمشكلة

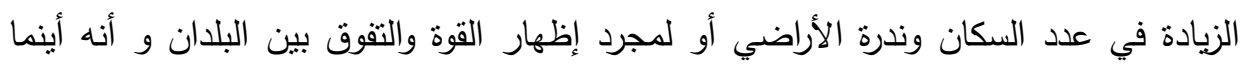

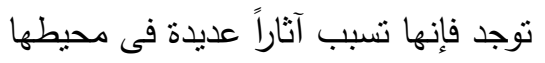

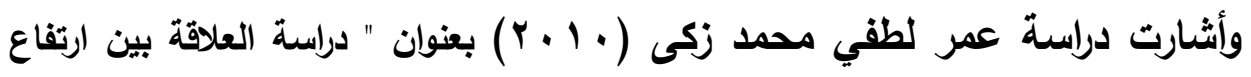
المباني في المناطق السكنية وكثافتها دراسة تطبيقية على القاهرة الكبرى"V إلي أن زيادة حجم

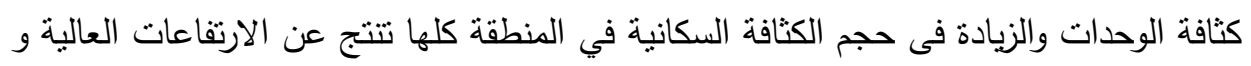
من ثم تعتبر الارتفاعات العالية هى احد الأسباب الرئيسية في زيادة الكثافة السكانية وتأثيراتها 


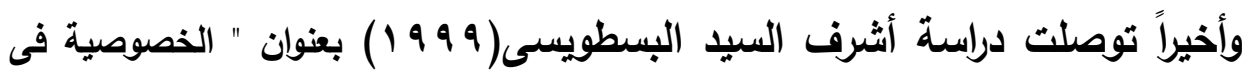
تخطيط وتصميم المناطق السكنية " إلي أن الخصوصية واحدة من المعايير الرئيسية في

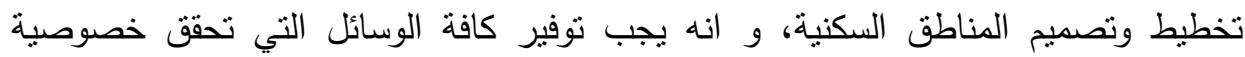

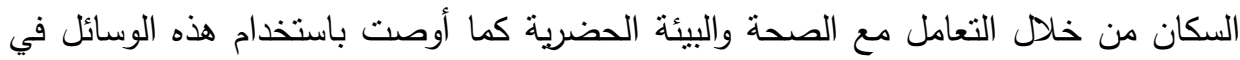
المستقبل ومراعاة أن توضع ضمن معايير تصميم المناطق السكنية المخططة من اجل المساعدة السكاة فى توفير بيئة أفضل للسكان.

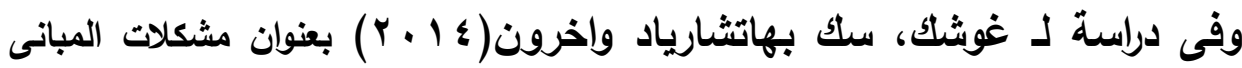
العالية بسبب قوى الرياح - دراسة حالة - استعرضت تاريخ تطور المباني العالية في الهند

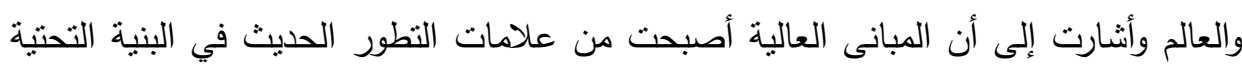

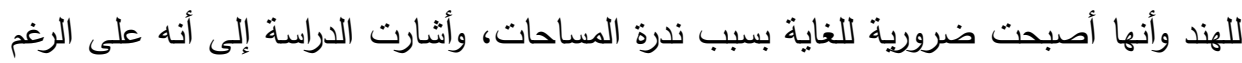

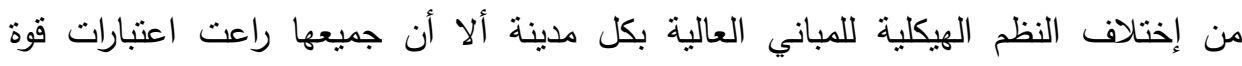

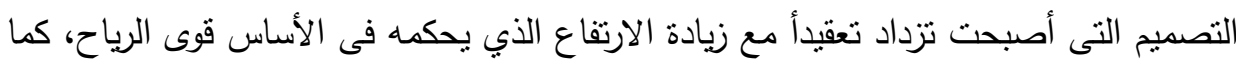

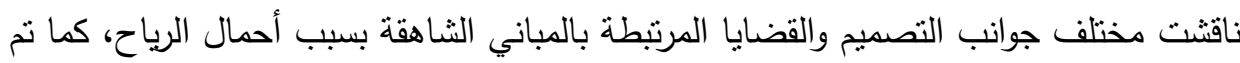
عرض دراسة حالة لعدد من المبانى العالية مختلفة الارتفاع من حيث تحميل الرياح وحسابها

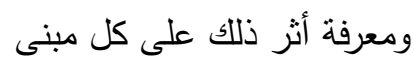

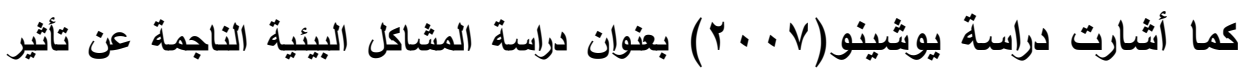
تكلس المباني السكنية الثناهقة باستخام نموذج كوميس إلى أن هناك العديد من المشكلات

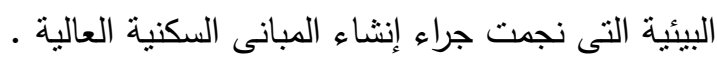

\section{الإطالر اللنظريه للتصراسة}

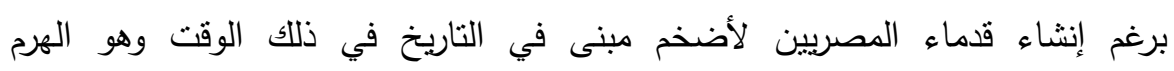

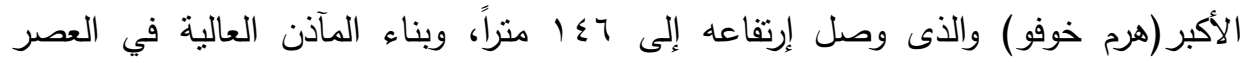

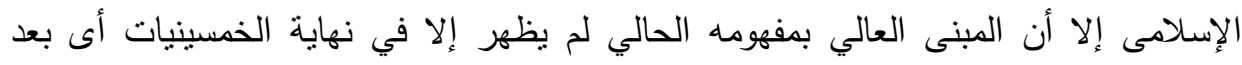
ظهور وإنتشار إستعمال الحديد والخراسنة في المباني، ومن أهم تلك المباني:

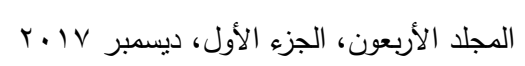




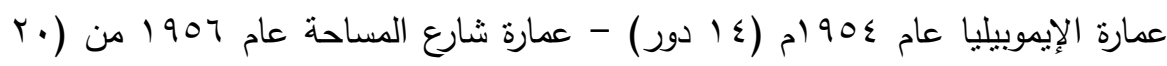

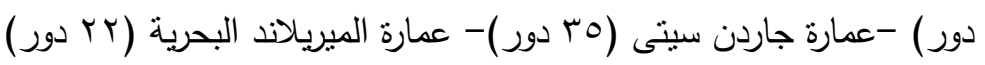

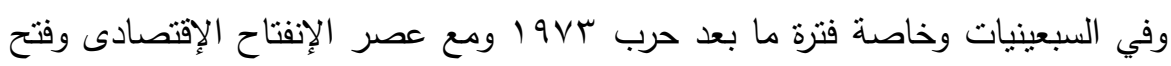

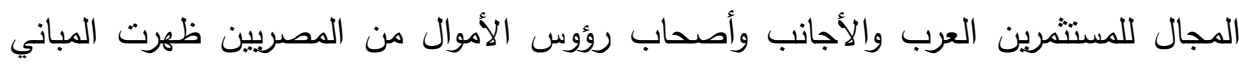

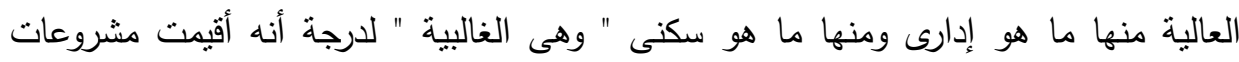

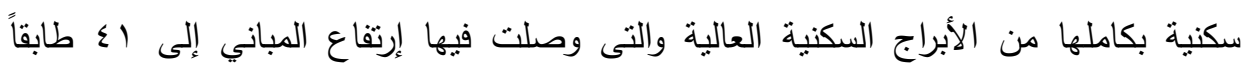

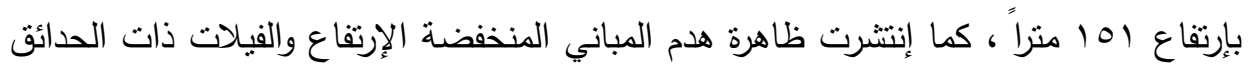

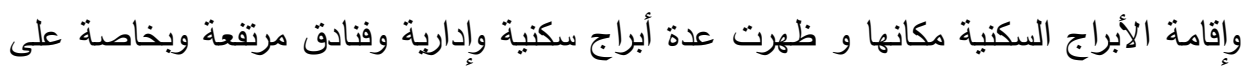

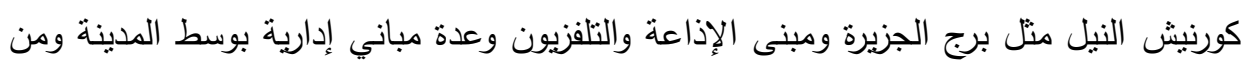

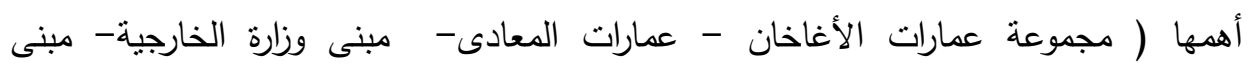

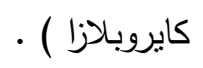

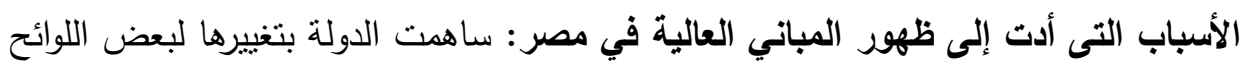

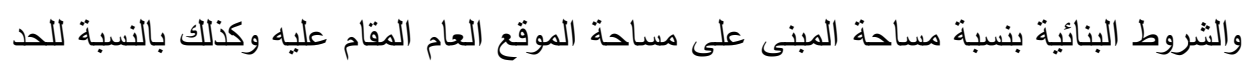

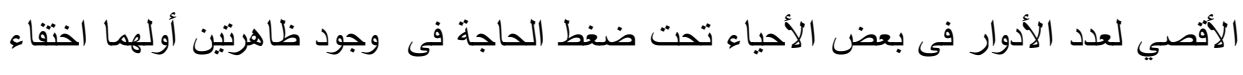

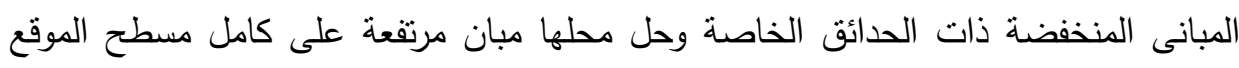

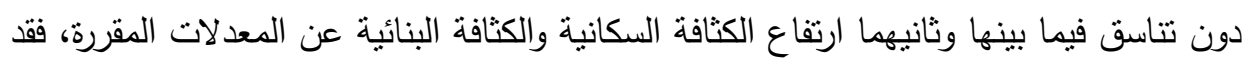

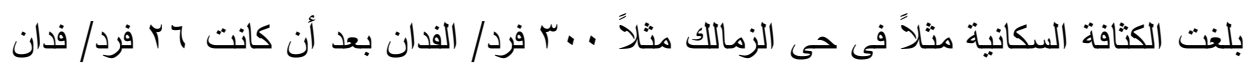

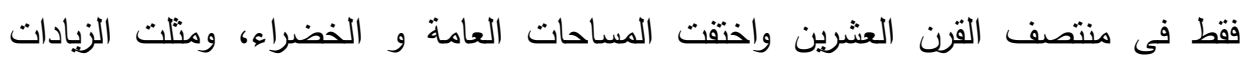

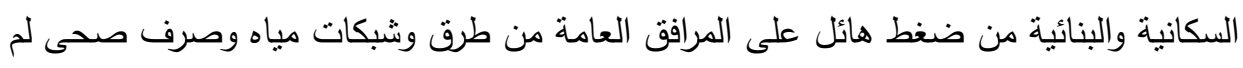

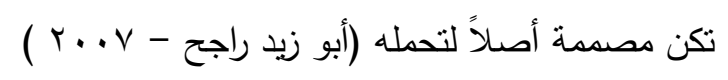

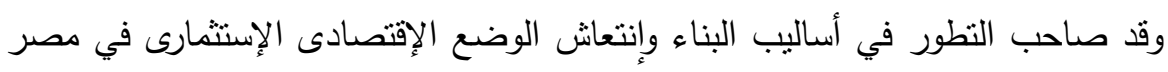

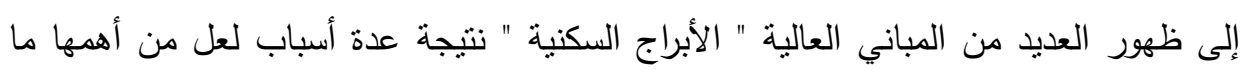
يلي: 


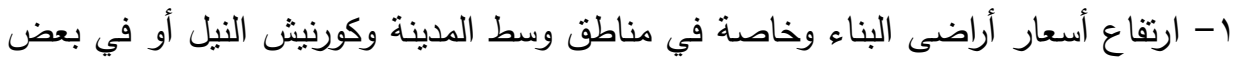
المناطق مثل المهندسين والزمالك أو شواطئ البحر في الأسكندرية.

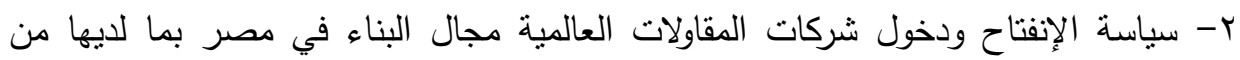
وسائل ونظم بناء حديثة، بالإضافة إلى الدعاية التى تعود على الثركات المنفذة أو مالك المشروع. r- النظرة الإستتمارية إلى المبنى العالى على أساس تعويض تكاليف البناء وأسعار الأراضى

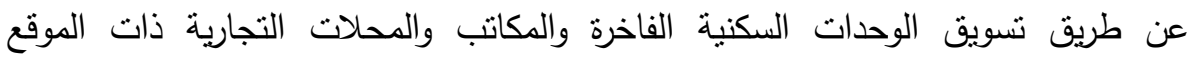
المتميز ه- السياسات التى تتجع القطاع الخاص على إقامة مبانى عالية لتوفير المساحات اللازمة من المكاتب للإستعمال الخاص أو بهدف الاستثمار .

ردود الفعل تجاه إستعمال المبانى العالية وظهورها فى المدن: لقد أثارت المبانى العالية نقاشاً كبيراً بين كثثر من الناس من المهندسين والمعماريين والسياسيين ورجال علم الإجتماع فى معظم المدن الكبرى من عواصم الدول وكان منهم لمؤيدين لها ومنهم من إنتقوها ورفضوا إقامتها فى ونى

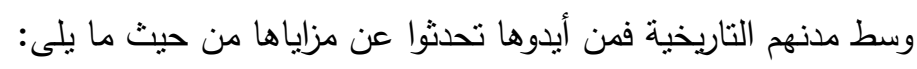

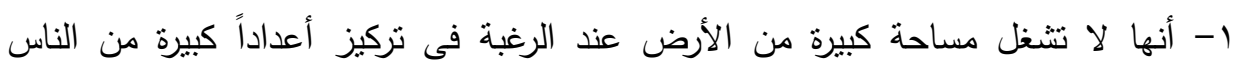

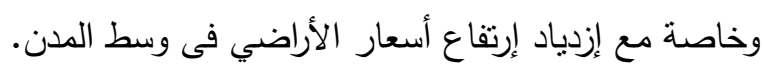

ץ- تحقق الكفاءة فى إدارة أعمال الشركات الكبرى التى يعمل بها آلاف الإضى الموظفين، فهلا تعطى

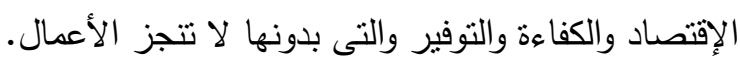

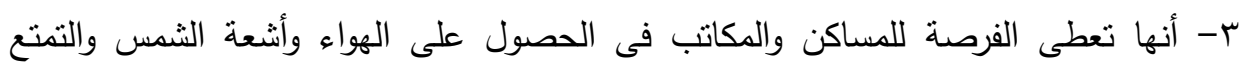

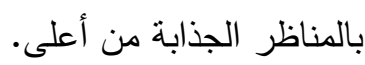

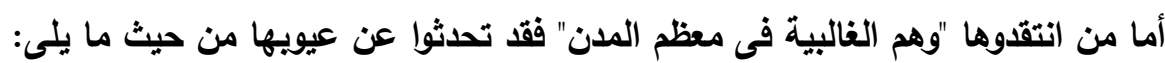

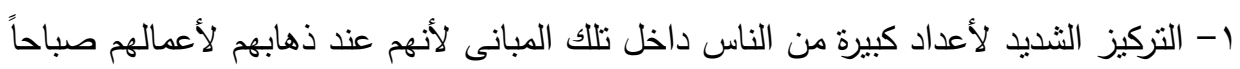

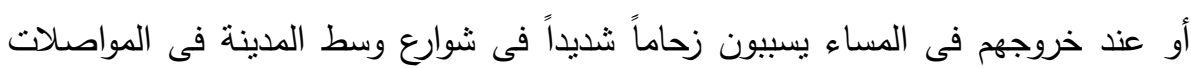


r- أعداد السيارات الرهيبة النى تسبب ازدحام الثوارع وإرباك حركة المرور وتوقفها تماماً أحياناً

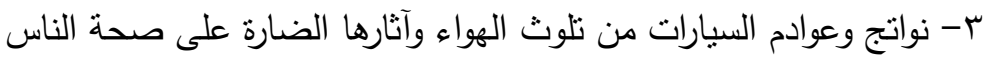

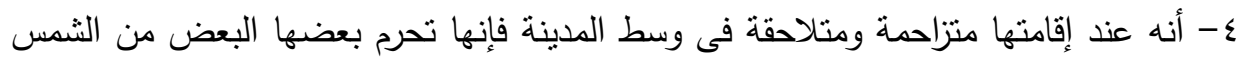

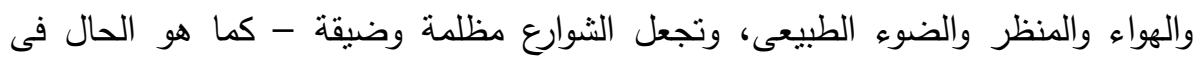
نيويورك. 0- نسبب هذه المبانى بإرثاعانها الثاهقة تغييراً للطابع والمنظر العام للمدن وطغيانها على الثى المبانى والآثار التاريخية بها. (مدحت محمد عبد المجيد الثناذلى - (191) )

\section{مهاسهيم الكراسما}

المشكلة - المشكلة الاجتماعية - المباني العالية " الأبراج السكنية "

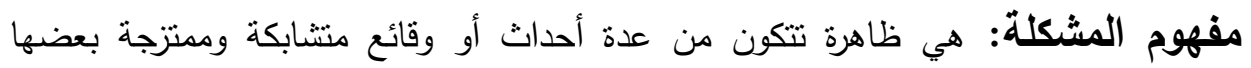

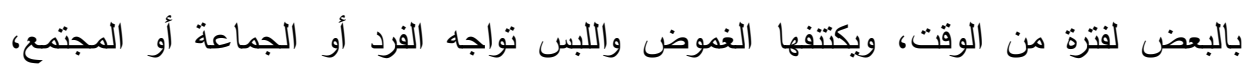

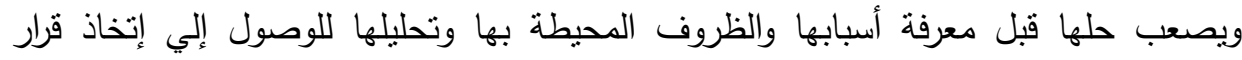

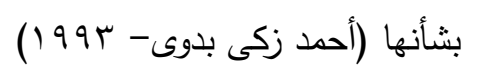

مفهوم المشكلة الاجتماعية: وتعرف بأنها " الخلل أو التدهور فى النظام البيئى بما ينجم

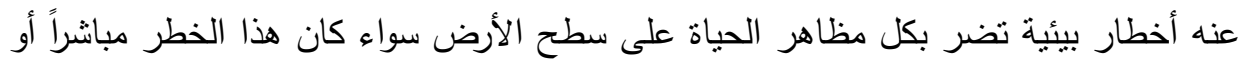
غير مباشر (G.rchhatwal , 1998)

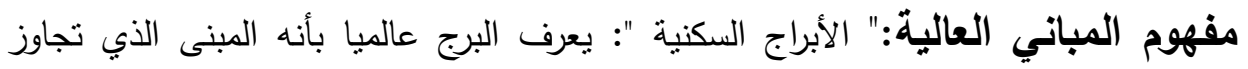

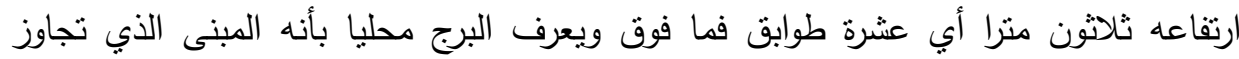
ارتفاعه ستة عثرة منرا أي خمسة طوابق فما فوق.

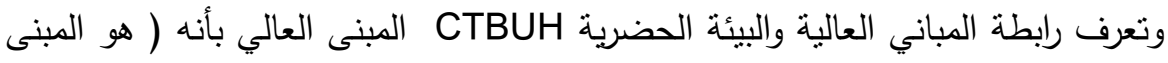

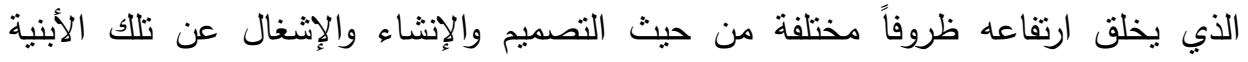

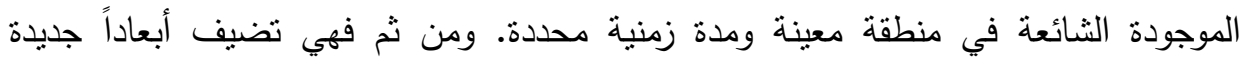
اللتعريف وهي المكان والزمان ومن ثم التقدم التكلوجي وقت انثائها) (Buyukozturk,2004)

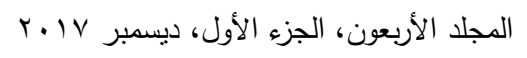


كما عرف المؤتمر العالمي للسلامة من الحرائق في المباني الثاهقة الأبراج الثشاهقة بأنها

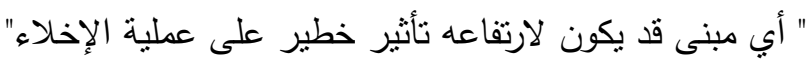

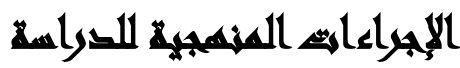

نوع الاراسة: دراسة وصفية تحليلية مقارنة للمشكلات الاجتماعية والنفسية والبيئية المرتبطة بظاهرة الأبراج السكنية

$$
\text { منهج الدواسة: منهج المسح الاجتماعي بالعينة }
$$

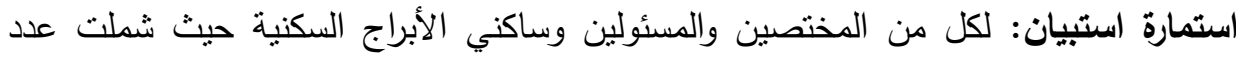

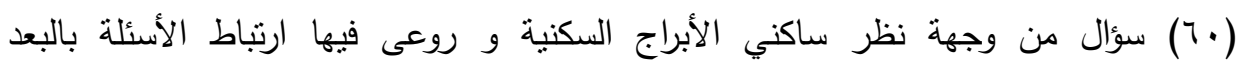

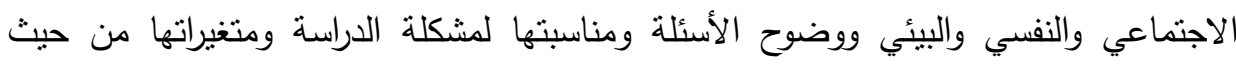

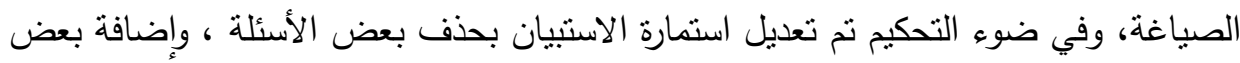

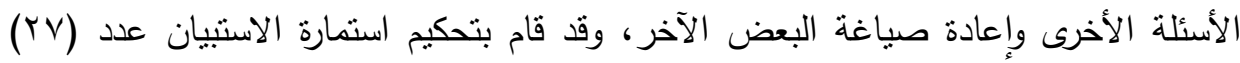

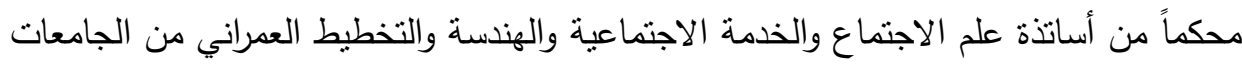
وكذللك المختصين في هذا المجال. مرحلة حساب ثبات وصدق استمارة الاستبيان:

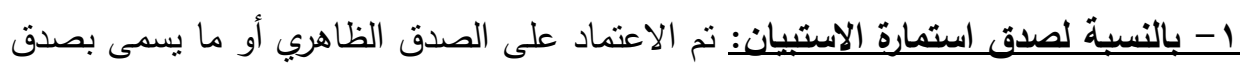

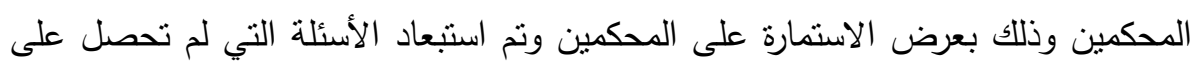

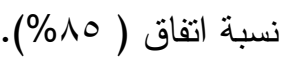

ب - بالنسبة لثبات استمارة الاستبيان: يعرف كارمينز وزيلر (1991) الثبات على مقياس الدقة

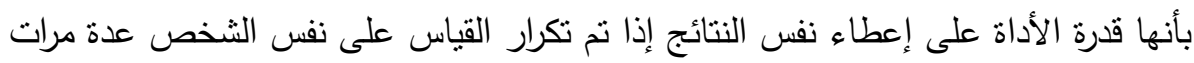
في نفس الظروف. والثبات في اغلب حالاته هو معامل ارتباط، ويقصد به مدى ارتباط قراءات نتائج القياس المتكررة، ومن ثم يحسب معامل ارتباط بين نتائج القياس في المرة

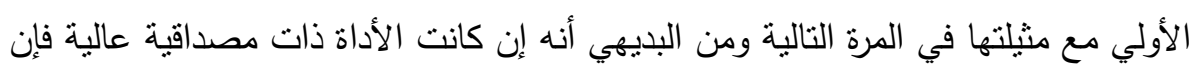

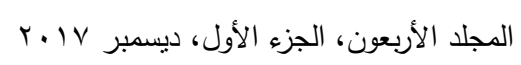


نتائج المرات التالية ستكون منماتلة أو منطبقة مع نتائج القياس الأول. بالإضافة إلى ذلك

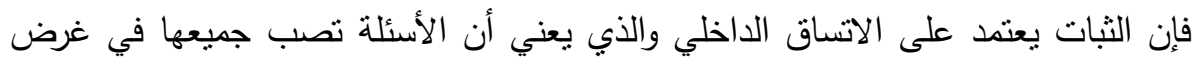

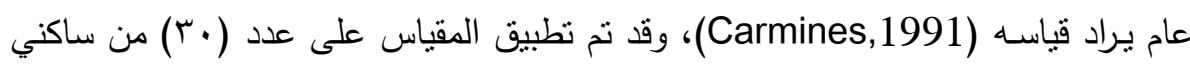
الأبراج السكنية بمعدل 10 شقة من كل منطقة من مناطق الدراسة وهى حلمية الزيتون

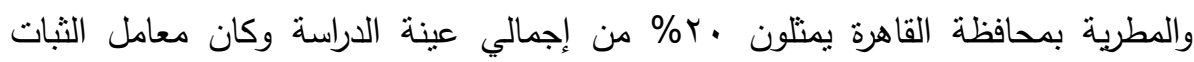
(AV) المقابلة: تعد المقابلة أداة مهمة للحصول على المعلومات من خلال مصادرها البشرية وتتنخدم

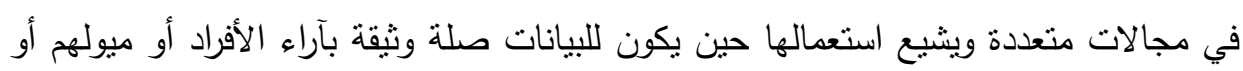

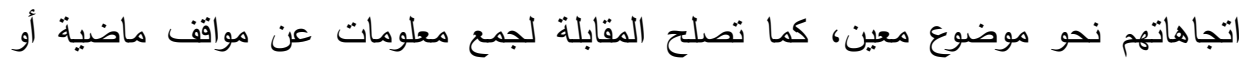

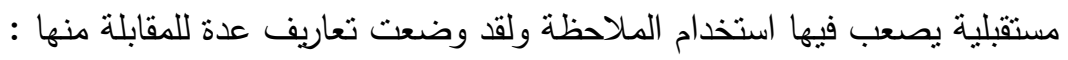
تعريف بنجهام (Bingham): هى المحادثة الجادة الموجهة نحو هدف محدد غير مجرد

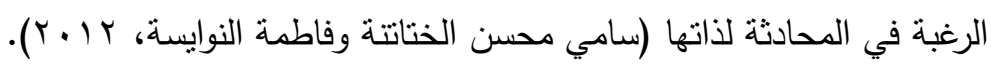
تعريف انجلش وانجلث : هى محادثة موجهة يقوم بها شخص مع شخص آخر أو أشخاص

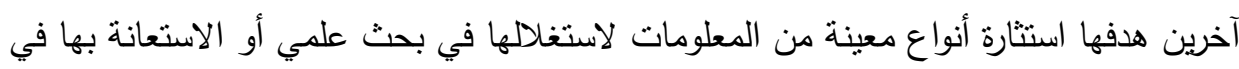

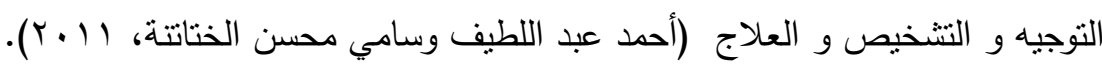
تعريف جاهودا : هى " التبادل اللفظي الذي يتم وجها لوجه بين القائم بالمقابلة بين شخص آخر آخر

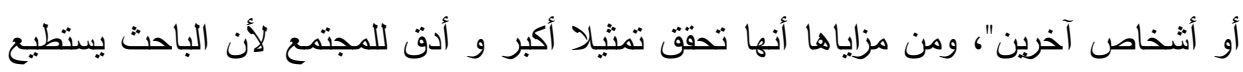

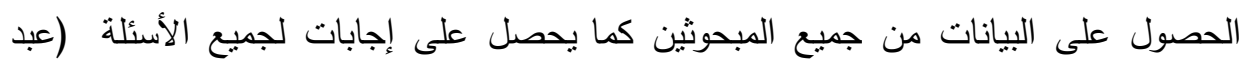

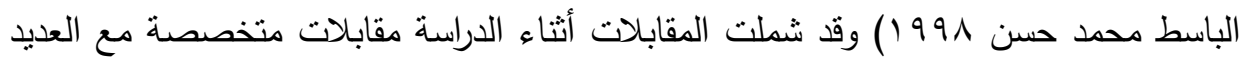

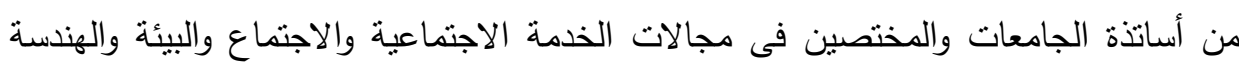

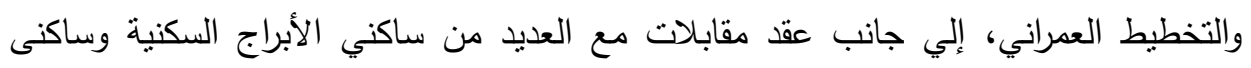


دراسة الحالة: يستخدم منهج دراسة الحالة لجمع البيانات عن ظاهرة أو وحدة ما وتصنيفها

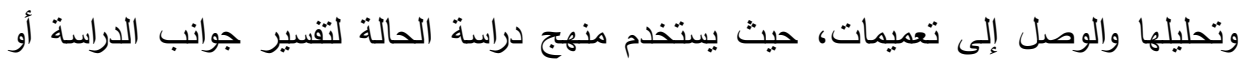
النتائج بصورة مستفيضة،، فعلى الرغم من أهمية التحليل الكمي الإحصائي في البحوث العلى دلهية

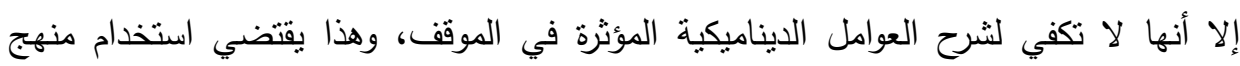

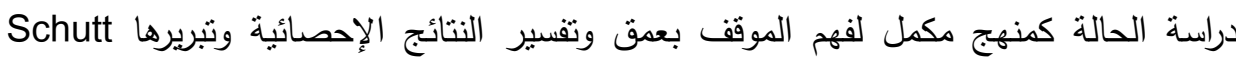

وقد تم أخذ عينة من منطقتي الدراسة بحلمية الزينون والمطرية كدراسة حالة لأحد أبراج كل منطقة وتم معرفة الخصائص الاجنماعية والاقتصادية والبيئية للمنطقتين.

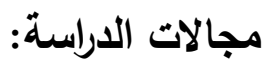
أ- المجال البشري: ساكني الأبراج السكنية والتحديد ساكنى الأدوار العليا من الطابق الساد

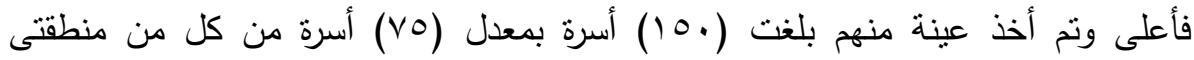
الدراسة وهما حلمية الزيتون والمطرية ب- المجال المكاني للاراسة: تم اختيار منطقتي حلمية الزيتون و المطرية بمحافظة القاهرة للاراسة لعدة أسباب منها: ا • من حيث النثأة : تعتبر المنطقتين من المناطق القديمة في القاهرة

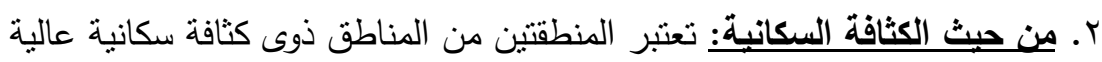
r. من حيث توافر الخدمات: تتوافر فى المنطقتين العديد من الخدمات المختلفة التى تشجع بعض المستثرين على هدم الفيلات والقيام بيناء الأبراج السكنية مكانها

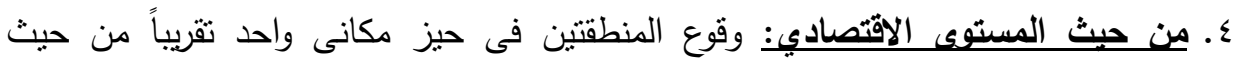
الحدود مما يتقارب معه المستوى الاقتصادي إلي حد ما ومما يسهل من المهمة أثناء القيام بالدراسة الميدانية

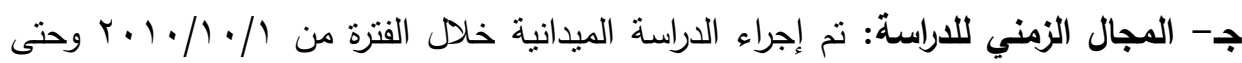
$r .11 / 1 / 10$ 


\section{نمانيج الصواسلة}

أبرزت الدراسة عدداً من النتائج لعل من أهمها ما يوضحه الجدول رقم (1) فى المقارنة

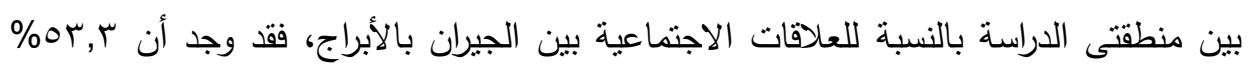

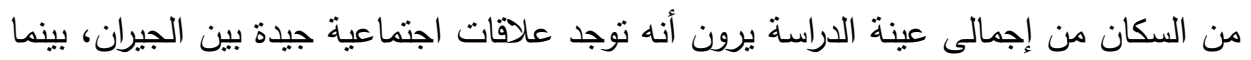

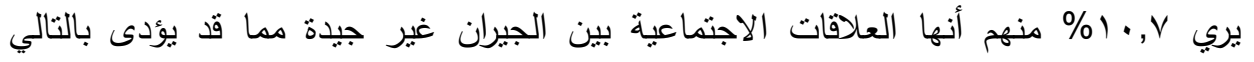

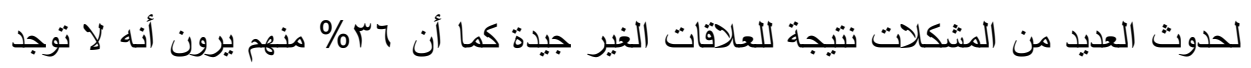

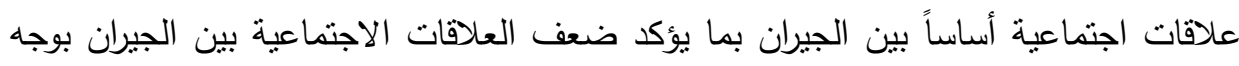

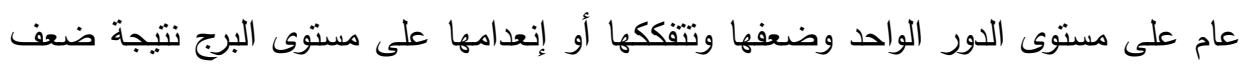

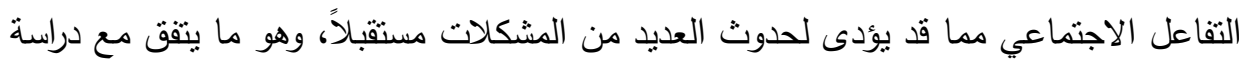

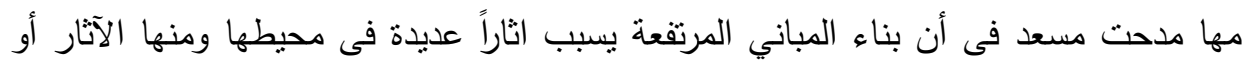

المشكلات الاجتماعية .

جدول رقم(1) : مقارنة بين منطقتي الدراسة بالنسبة للعلاقات الاجنماعية بين الجيران بالأبراج

\begin{tabular}{|c|c|c|c|c|c|c|c|c|c|}
\hline إلنسب & \multicolumn{2}{|c|}{ النسبة من إجمالي } & \multirow{2}{*}{ المجموع } & \multirow{2}{*}{$\begin{array}{c}\text { المئوية } \\
\text { \% }\end{array}$} & \multirow{2}{*}{ المبرباجة } & \multirow{2}{*}{$\begin{array}{c}\text { المئوية } \\
\text { \% }\end{array}$} & \multirow{2}{*}{ الزبراج } & \multirow{2}{*}{ الاجت شاجتايف } & \\
\hline$\%$ & المطرية & الزيتونة & & & & & & & e \\
\hline$\%$ \%० & \%Yr & \%r. & A. & $\% \leq 7, V$ & To & $\%$ \% . & $\varepsilon 0$ & كويسة & 1 \\
\hline$\% 11$ & $\% \vee$ & $\% 乞$ & 17 & \%וr, & 1. & $\% \wedge$ & 7 & كويسة & $T$ \\
\hline \%rq & $\%$ \%. & $\% 17$ & $0 \leqslant$ & $\%$ & r. & \%rr & T乏 & علاقة توجد & $\mu$ \\
\hline$\% 1 \ldots$ & $\% 0$. & $\% 0$. & 10. & $\% 1 \ldots$ & Vo & $\% 1 \ldots$ & Vo & المجموع & \\
\hline
\end{tabular}

ويوضح الجدول رقم (Y) مقارنة بين منطقتى الدراسة بالنسبة لأسباب سوء العلاقات الاجتماعية بين المبحوثين وجيرانهم كالتالى :

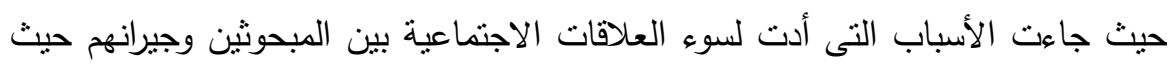

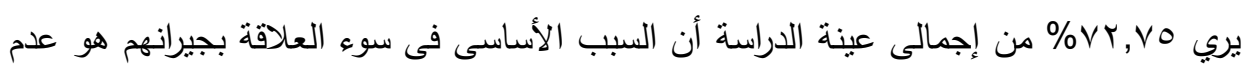

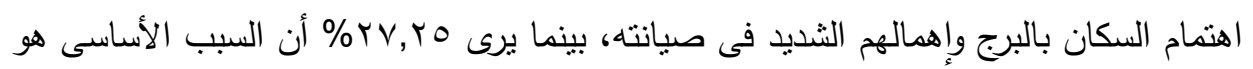


عدم انتماء السكان للبرج وعدم خوف كل منهم على الآخر ـ كما يوضح الجدول رقم (r) مقارنة بين منطقتى الدراسة بالنسبة لشعور سكانى الأبراج السكنية بالأمان في حالات الحرائق أو بورة

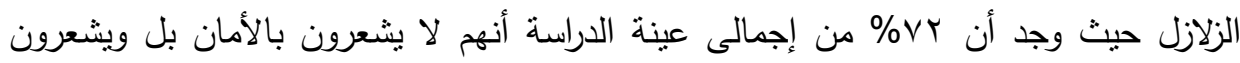

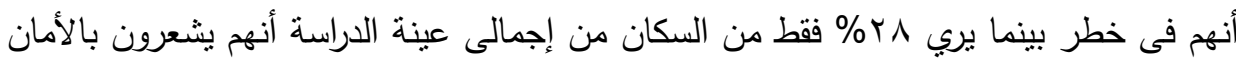

جدول رقم(ץ): مقارنة بين منطقتى الدراسة بالنسبة لشعورهم بالأمان في حالات الحرائق أو

\begin{tabular}{|c|c|c|c|c|c|c|c|c|c|}
\hline & & & & & & & الزلازل & & \\
\hline \multirow{2}{*}{ إلنمبالى } & \multicolumn{2}{|c|}{ إجمالي عينة الدية } & \multirow[b]{2}{*}{ المجموع } & \multirow{2}{*}{$\begin{array}{l}\text { النئوية } \\
\text { \% }\end{array}$} & \multirow{2}{*}{ البكراج } & \multirow{2}{*}{$\begin{array}{l}\text { المئوية } \\
\text { \% }\end{array}$} & \multirow{2}{*}{ الزبئبراج } & \multirow{2}{*}{ 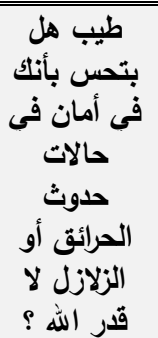 } & \\
\hline & البطرية & ألزيتونة & & & & & & & \\
\hline$\%$ \%イᄉ & $\% 1$. & $\% \backslash \wedge$ & $\varepsilon Y$ & \%r. & 10 & \%rч & TV & نعم & 1 \\
\hline$\% \vee r$ & $\% \varepsilon$. & \%rr & 1.1 & $\% \wedge$. & 7. & $\% т \varepsilon$ & $\varepsilon \Lambda$ & $y$ & $r$ \\
\hline$\% 1 \ldots$ & $\% 0$. & $\% 0$. & 10. & $\% 1 \ldots$ & Vo & $\% 1 \ldots$ & Vo & المجموع & \\
\hline
\end{tabular}

أما بخصوص أسباب عدم تحقيق السكن بالأبراج ما كان يتمناه المبحوثين فيوضح الجدول ، ، هو

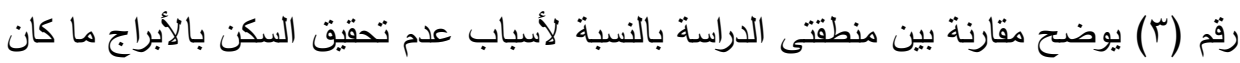
يتمناه المبحوثين فقل جاءت على النحو التالي: يري نسبة ؟, •ـr\% من المبحوثين أن تصميم الثقة غير مناسب

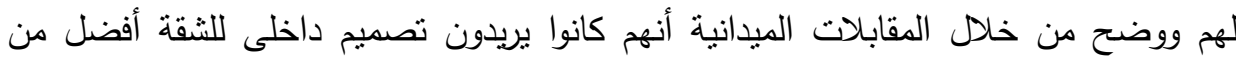

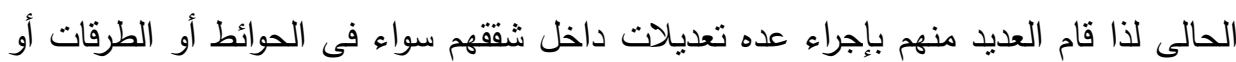

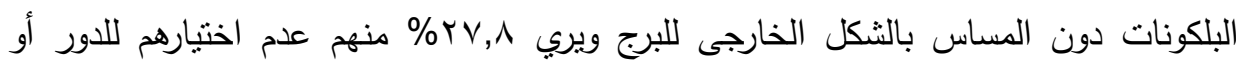

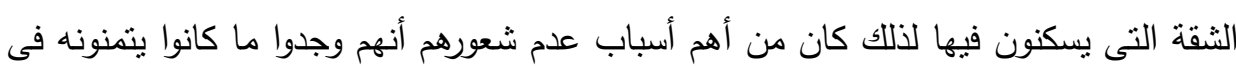

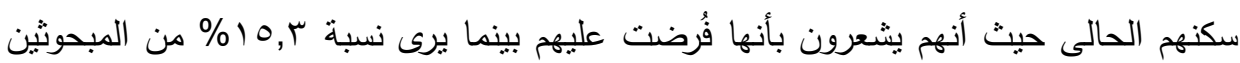

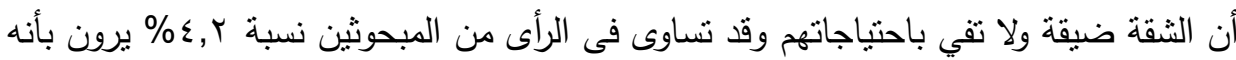

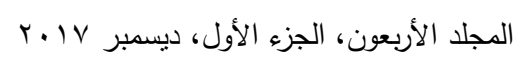


من ضمن الأسباب أيضاً أن الثقة لا تدخلها الثمس إلا نادراً وأنها جانبية وليست علي الثارع

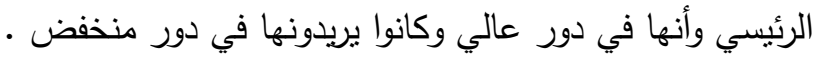
جدول رقم(ץ): يوضح مقارنة بين منطقىى الدراسة بالنسبة لأسباب عدم تحقيق السكن بالأبراج ما كان يتمناه المبحوثين

\begin{tabular}{|c|c|c|c|c|c|c|c|c|c|}
\hline \multirow{2}{*}{ إجمالى } & \multicolumn{2}{|c|}{ إجمالي عينة الدراسة من } & \multirow[b]{2}{*}{ المجموع } & \multirow{2}{*}{$\begin{array}{c}\text { النسية } \\
\text { \% }\end{array}$} & \multirow{2}{*}{ المطرية } & \multirow{2}{*}{$\begin{array}{l}\text { المئوية } \\
\text { \% }\end{array}$} & \multirow{2}{*}{ 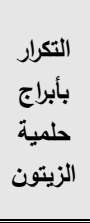 } & \multirow{2}{*}{ 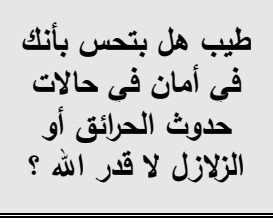 } & \multirow[b]{2}{*}{ r } \\
\hline & المطرية & 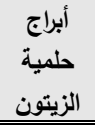 & & & & & & & \\
\hline$\% r, r$ & $\% 1 r, q$ & $\% 14, \vee$ & rr & \%rr,r & 1. & $\% \curlyvee \wedge, \uparrow$ & Ir & مناسب تصـميم الثـقة مـش & 1 \\
\hline$\% \backslash \bullet, r$ & $\% 7,9$ & $\% \wedge, r$ & 11 & $\% 14, \vee$ & - & $\% 1 \leq, r$ & 7 & بالأن الثقاتية ضيقة ولا تفي & r \\
\hline$\% \leq, Y$ & $\% \cdot, \cdot$ & $\% \varepsilon, r$ & $r$ & $\% \cdot, \cdot$ & - & $\% \vee, 1$ & $r$ & 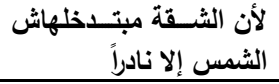 & $r$ \\
\hline$\% \leq, r$ & $\% \cdot, \cdot$ & $\% \varepsilon, r$ & $r$ & $\% 14, v$ & 。 & $\% \vee, 1$ & $r$ & لأن الثـارعة جانبيـة ومـش & $\varepsilon$ \\
\hline$\%$ rv, & $\% \curlyvee, 9$ & $\% r \cdot, \wedge$ & r. & $\% \cdot$, & - & $\%$ \% , v & 10 & 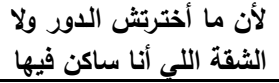 & 0 \\
\hline$\% \varepsilon, r$ & $\% \cdot, \cdot$ & $\%$ \&,r & $r$ & $\% \cdot$, & - & $\% \vee, 1$ & $r$ & منألنا كنت الثقة فيز دور عالي دور & 7 \\
\hline$\% \cdot$, & $\% \cdot, \cdot$ & $\% \cdot$, & - & $\% \cdot, \cdot$ & - & $\% \cdot, \cdot$ & - & 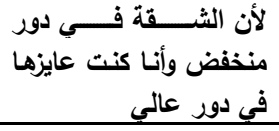 & V \\
\hline$\% \cdot$, & $\% \cdot, \cdot$ & $\% \cdot, \cdot$ & - & $\% \cdot$, & - & $\% \cdot, \cdot$ & - & 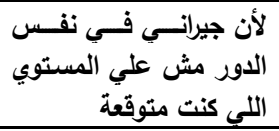 & $\wedge$ \\
\hline$\% \backslash$ ४ q & $\% \backslash r, q$ & $\% \cdot$, & 1. & \%rr,r & 1. & $\% \cdot, \cdot$ & - & أخري تذكر & 9 \\
\hline$\% 1 \ldots$ & $\% \leqslant 1, v$ & $\% \diamond \wedge, r$ & Vr & $\% 1 \ldots$ & r. & $\% 1 \ldots$ & $\leqslant r$ & المجموع & \\
\hline
\end{tabular}


كما جاء بالدراسـة إختلاف نوعية المشكلات التى يعانى منها سـاكنى الأبراج السكنية حيث

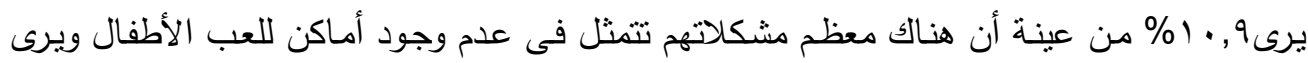

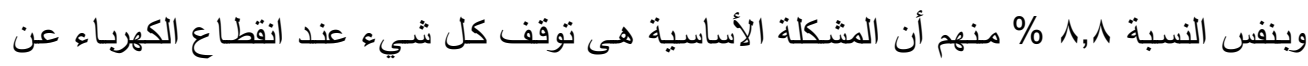

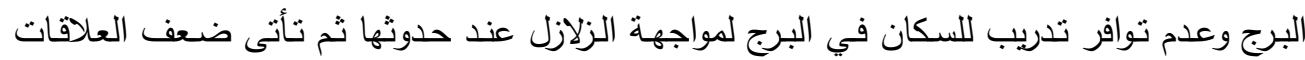

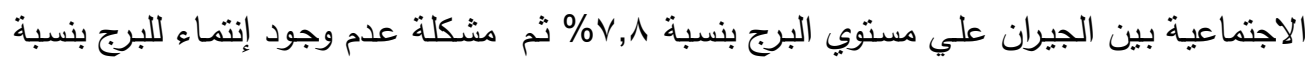
\% \&,V

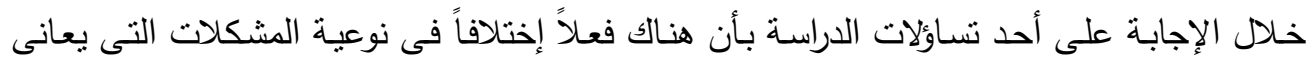

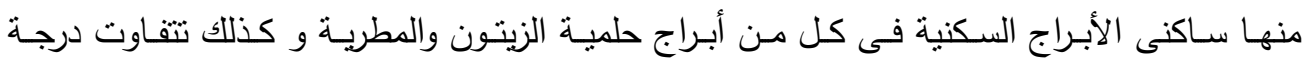

كما أبرزت الدراسة عدداً من النتائج لعل من أهمها ما يلي: وجود مشكلات إجتماعية تمثلت فى الآتى:

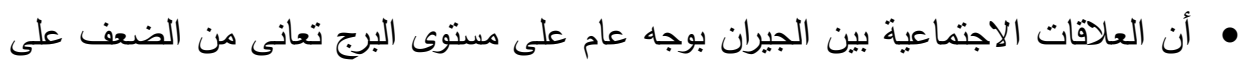

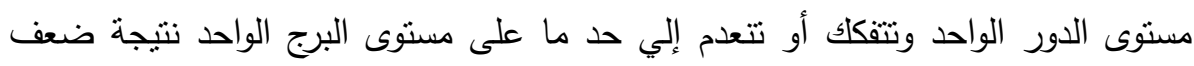

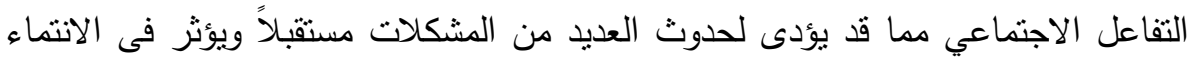

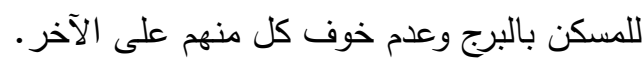
• • عدم إحساس ساكنى الأبراج بالانتماء لأبراجهم مما أدى لإهمال المرافق وعدم صبيانتها

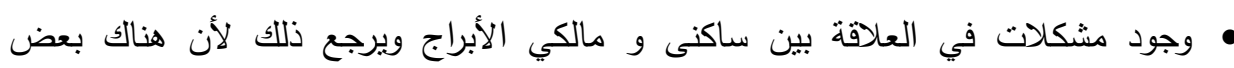

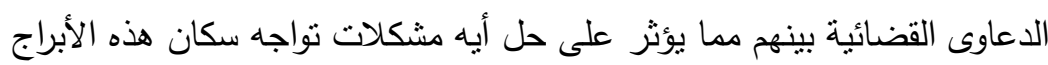
وجود مشكلات نفسية تمثلت فى الأتي: • لم يتم مراعاة الخصوصية عند تصميم الأبراج السكنية حيث أنه أحياناً يكثف الجيران

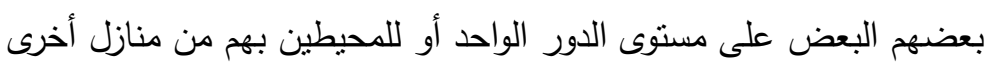

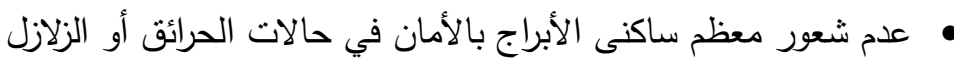


• لم يحقق تصميم الأبراج متطلبات الأطفال المختلفة من مساحات كافية لممارسة أنشطتهم

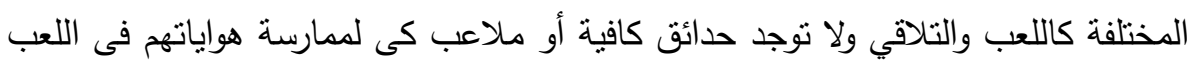
والمرح مما يسبب لهم الكبت والإحباط من لعبهم داخل شققهم وعدم تلاقيهر مع أقرانهم.

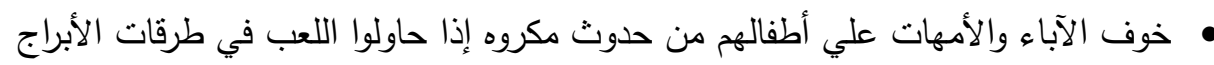

$$
\text { وجود مشكلات بيئية تمثلت فى الاتى: }
$$

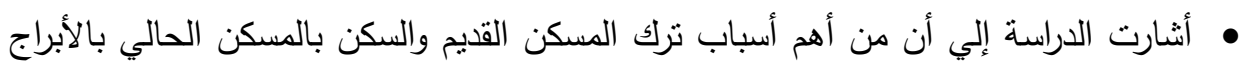
الازدحام والضوضاء وتلوث المنطقة السابقة وعدم وفاء المسكن القديم لكافة احتياجاتهم في المنطقة القديمة بالإضافة إلي زيادة الدخل وعدم مناسبة منطقة السكن السابقة و انتقال موقع

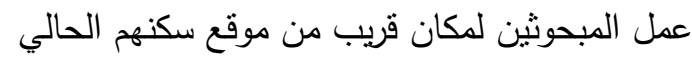

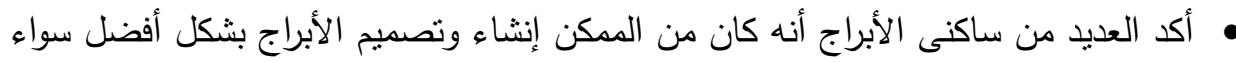

$$
\text { فى اختيار الموقع أو التصميم الداخلي أو الخارجي للأبراج. }
$$

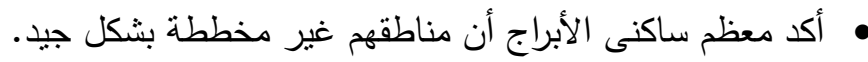

$$
\text { وجود مشكلات أخرى تمثلت فى الاتى : }
$$

• انقطاع الكهرباء وضعف المياه وانقطاعها أحياناً نتيجة الضغط على المرافق العامة من مياه

$$
\text { و كهرباء وصرف صحى مما يسبب كارثة وخاصة لساكنى الأدوار العليا. }
$$

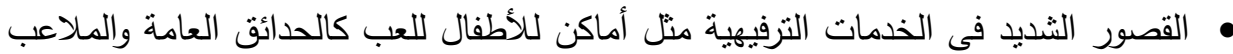

$$
\text { والملاهي والنوادي. }
$$

• إهمال الخدمات الأمنية كعدم وجود ق قسم للشرطة أو نقطة شرطة أو وحدات مطافي قريبة

$$
\text { • عدم وجود أى تدابير وقائية ضد الحرائق أو الزلازل أو أيه كوارث. }
$$

\section{تمويامي التراسة}

1 - ضرورة نطوير التشريعات العمرانية والقوانين المنظمة للعمران وخاصة الأبراج السكنية

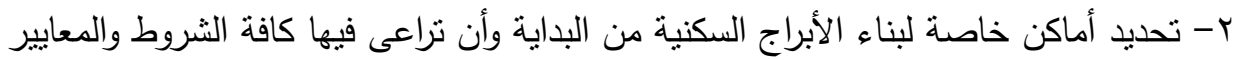
البيئية والتخطيطية والتصميمية والصحية والاجتماعية والنفسية. 
ب- سرعة وضع قوانين تتظم العلاقة بين مالكي الأبراج وسكانها ـ

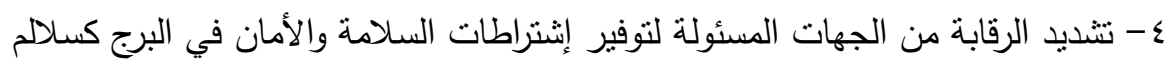
للهروب في حالات الكوارث، وكذللك التشديد على ضرورة وجود جراج لسيارات السكان.

0- توفير تدريب جيد من جانب المسئولين للسكان في البرج لمواجهة الزلازل عند حدوثنها

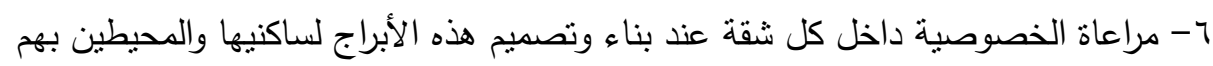

\section{sall}

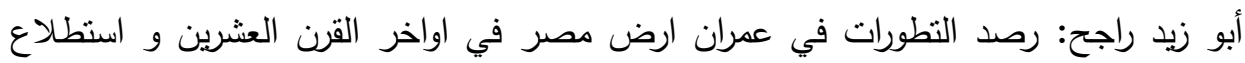

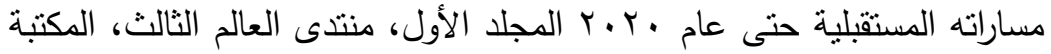

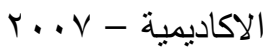

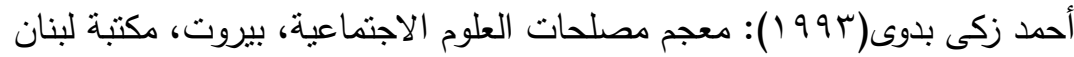

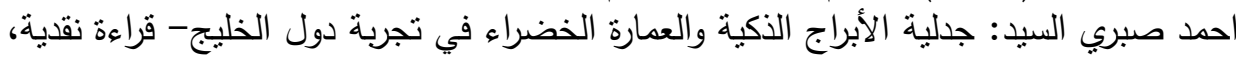

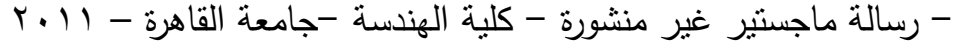

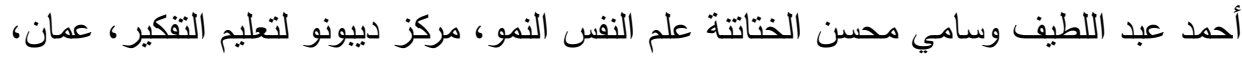

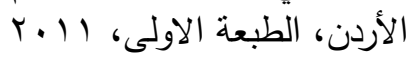

أشرف السيد البسطويسى(1999 (1): الخصوص، الأبية فى تخطيط وتصميم المناطق السكنية، رسالة

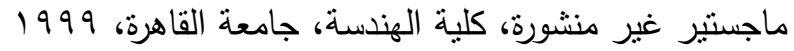

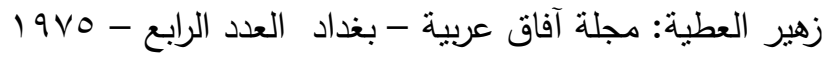

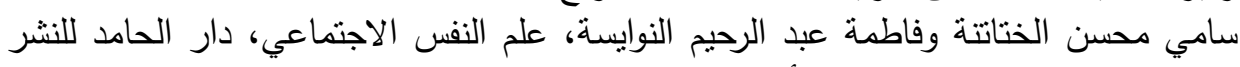

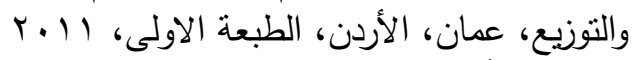

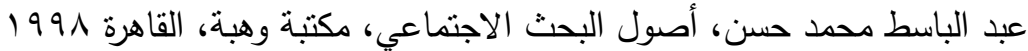

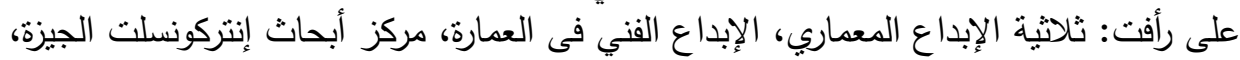

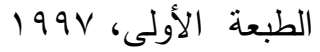

على رأفت(997(1): ثلاثية الإبداع المعماري، الإبداع المادي، مركز أبحاث إنتركونسلت -

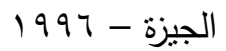

عمر لطفي محد زكى( • ( • ب): دراسة العلاقة بين ارتفاع المباني في المناطق السكنية وكثافتها

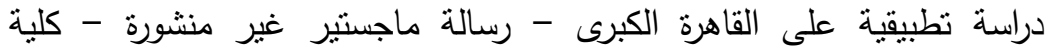
الهندسة - جامعة القاهرة

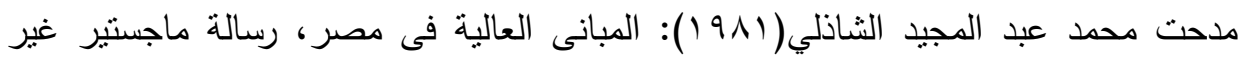
منشورة، كلية الهندسة، جامعة القالهرة 
مها مدحت مسعد(Y Y Y): نحو معايير تقييم لدراسة الآثار الناتجة من المبانى العالية فى

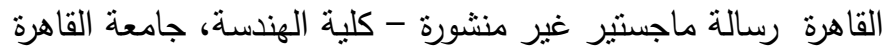

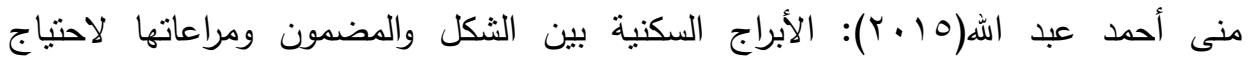

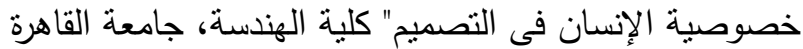

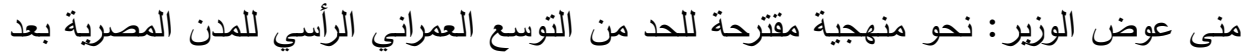

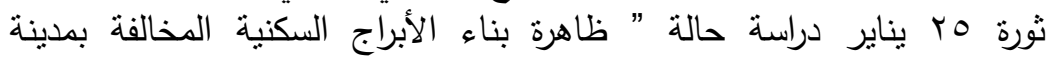

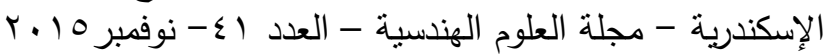

Carmines, E. G. \& Zeller, R.AR. Reliability and validity assessment. 1991.

Buyukozturk, Dr.Oral, High-Rise Buildings : Evolution and Innovations ,Toronto , Ontario , Canada , 2004

Earl rubington \& martin s . Weinberg, the study of social problems :seven perspectives ,oxford univ. Press, n y, 1995

G.r chhatwal : encyclopedia of environmental management (new Delhi India) publication pvt ltd , 1998

Hok, Design criteria for review of tall building proposals, city of Toronto, HokArchitects corporation, June, 2006

Schutt R. Investigating The social Work: the process and practice of Research Thcusand Oaks. CA: Pine Forge Press. (1996).

Will, Maunsell Ltd, Herbert Girardet, Urban Futures , Greg Cox , Oscar Faber Ltd, Tall Buildings and Sustainability, Corporation of London , 2002 
عبد الباسط محمد عبد المعطى وآخرون

\title{
THE SOCIO-PSYCHOLOGICAL AND \\ ENVIRONMENTAL PROBLEMS RELATED TO \\ RESIDENTIAL TOWERS PHENOMENA ( COMPARATIVE ECOLOGICAL STUDY
}

\begin{abstract}
Abd El-Moety, A. M. ${ }^{(1)}$; Nozha, H. K. M. ${ }^{(2)}$ and Abd El-Aziz, S. S. ${ }^{(3)}$
1) Faculty of Girls of Literature, Science and Education, Ain Shams University 2) Faculty of Regional and Urban Planning, Cairo University3) General Authority for Physical Planning
\end{abstract}

\begin{abstract}
The study aims to identify The Socio-Psychological and Environmental Problems Related to Residential Towers Phenomena through Comparative Ecological Study in different regions to identify the most important problems that resulted from the construction of these residential towers, to contribute to access to solutions or reduce the effects or reduce If possible in the future .

The importance of the study is to be an attempt to study the phenomenon of residential towers as one of the phenomena that spread widely in the Egyptian society, especially in areas that did not plan and did not prepare for the construction of these towers, which led to the emergence of many problems, including social problems, psychological and environmental problems and increasing day by day, Dimensional solutions to reach effective solutions to address them.

The study was based on the analytical and comparative descriptive methods. A sample of (150) individual was selected for (75) individual for each of the residents of the towers in the areas of Helmiyeh El Zaitoun and El Matareya.

The study used a number of tools, including questionnaire, interview and case study. It also used several sources: field visits, interviews with experts, documents, records, photographs and maps.
\end{abstract}

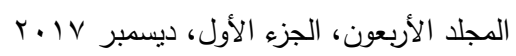




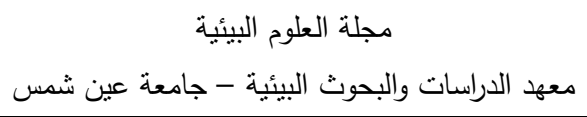

The results of the study indicate that the reasons for the trend of housing in the residential towers were increasing household income, congestion, noise, pollution and the failure of the former housing for all their needs. The study also revealed the emergence of many problems due to the construction of residential towers such as weak social relations between residents of residential towers and their disintegration, And the lack of interest of its residents in the maintenance of facilities, and the lack of privacy in the design of most of them and not to meet the requirements of different children, in addition to that the interruption of electricity depends with everything completely electricity, water, elevators, etc. 